\title{
AS QUESTÕES ÉTNICO-RACIAIS NAS AULAS DE INGLÊS INSTRUMENTAL DO IFRJ SOB A ÓTICA DA PEDAGOGIA DOS MULTILETRAMENTOS
}

\section{ETHNIC AND RACIAL ISSUES IN ESP CLASSES AT IFRJ IN THE LIGHT OF MULTILITERACIES PEDAGOGY}

\author{
Vanessa Moreno Mota * \\ Heloise Vasconcellos Gomes Thompson **
}

\begin{abstract}
Resumo: Este artigo analisa os resultados obtidos por meio da abordagem de questões étnico-raciais em aulas de Inglês Instrumental com turmas do curso técnico concomitante/subsequente em Administração, no IFRJ. Esta pesquisa teve como objetivos apresentar possibilidades para a adoção de um ensino transgressivo de inglês (HOOKS, 2017) e investigar os benefícios obtidos a partir da promoção dos multiletramentos (ROJO, 2013) dos aprendizes através do debate de questões étnico-raciais na sociedade, contribuindo para que sejam mais autônomos (OXFORD, 2003; NICOLAIDES et al., 2013). Como metodologia, realizaram-se tarefas, conciliando a temática da Consciência Negra e a aproximação dos alunos às tecnologias digitais através do aplicativo Padlet. Por meio da análise do processo de criação de murais virtuais por parte dos alunos, constatou-se que sua aproximação com ferramentas digitais em sala de aula contribuiu para a promoção da autonomia, visto que os discentes assumiram o protagonismo do processo de ensino e aprendizagem.
\end{abstract}

Palavras-chave: Ensino de inglês. Autonomia. Novas tecnologias.

\begin{abstract}
This article analyzes the results achieved through the approach of ethnic and racial issues in ESP classes from an Administration course at IFRJ. This research aimed at presenting possibilities for the adoption of a transgressive teaching process (HOOKS, 2017) and investigating the benefits of promoting students multiliteracies (ROJO, 2013) through the debate of ethnic and racial issues in order to contribute to students' autonomy (NICOLAIDES et al., 2013). The methodology used was based on the proposal of activities involving the discussion of Black Awareness topics and also the attempt to bring students closer to new technologies through the use of Padlet. The analysis of the creation process of students' virtual walls made possible to conclude that the use of digital tools in classrooms contribute to the promotion of autonomy since students become protagonists of the learning process.
\end{abstract}

Keywords: English teaching. Autonomy. New Technologies.

\section{Introdução}

A disciplina de Inglês na Educação Básica, de maneira geral, costuma ser rodeada de crenças e mitos que nem sempre refletem a realidade do processo de ensino e aprendizagem de uma língua adicional. De acordo com Weden (1998), os aprendizes carregam consigo uma série de crenças acerca de como se aprende uma língua estrangeira e isso afeta diretamente seu desempenho em sala de aula. Madeira (2008) acrescenta que professores também possuem conceitos pré-formulados acerca do ensino

\footnotetext{
* Professora efetiva de Português e Inglês do Instituto Federal de Educação, Ciência e Tecnologia do Rio de Janeiro e Doutoranda em Linguística Aplicada pela Universidade Federal do Rio de Janeiro. vanessa.mota@ifrj.edu.br.

** Professora efetiva de Português e Inglês do Instituto Federal de Educação, Ciência e Tecnologia do Rio de Janeiro e Doutora em Língua Portuguesa pela Universidade Federal do Rio de Janeiro. heloise.thompson@ifrj.edu.br.
} 
de línguas e, muitas vezes, pautam suas práticas nas experiências que tiveram quando alunos. Sendo assim, as crenças envolvidas no processo de ensino e aprendizagem de línguas somadas a fatores como a quantidade de estudantes em sala, a desmotivação perante o aprendizado de uma língua estrangeira, o material didático que não é adequado ao público-alvo, entre outros, podem contribuir para uma abordagem mais conteudista e que não promove o desenvolvimento adequado dos discentes como cidadãos do mundo e capazes de utilizar o conhecimento adquirido para atuar no meio em que vivem (cf. COELHO, 2005; OLIVEIRA, 2009; HIRATA, 2012, entre outros).

No âmbito das escolas da Rede Federal, especialmente no Ensino Profissional e Tecnológico, além das crenças que são comuns a qualquer modalidade de ensino de línguas, tem-se o intuito de, por meio das disciplinas ofertadas, capacitar os alunos para a atuação em uma área técnica. Nesse sentido, as normativas que embasam o ensino profissional acabam por "respingar" em sala de aula, levando, muitas vezes, a um processo de ensino e aprendizagem que não parte das necessidades dos indivíduos nele envolvidos. Frigotto (2001, p. 80) comenta que:

(n)o projeto do governo federal, a organização e conteúdo básico explicitados na atual LDB e, em particular, nos pareceres e portarias que a regulamentam, a Educação Profissional subordina-se ao ideário do mercado e do capital e de um modelo de desenvolvimento excludente, concentrador de renda, predatório.

Sendo assim, apesar de oferecer educação de qualidade, de maneira geral, a rede de Ensino Profissional e Tecnológico se encontra sujeita às demandas do mercado. No que tange ao ensino de línguas, frequentemente, resume-se à abordagem de tópicos gramaticais, com vistas a agregar exclusivamente no exercício da função técnica enfocada pelo aluno em sua trajetória acadêmica. De acordo com Bender (2019, p. 29), "o educando que já se decidiu por uma área de atuação profissional poderá ter um maior interesse pelas aulas de inglês à medida que essas levarem em conta seus objetivos". Dantas, ao analisar as falas de professores de inglês do Instituto Federal do Rio Grande do Norte acerca do ensino da disciplina de Inglês Instrumental, defende que "não podemos desconsiderar o uso de uma abordagem mais voltada às demandas específicas da área escolhida por esse aluno" (DANTAS, 2017, p. 22).

Nesse contexto, constatamos que, no âmbito da Educação Profissional, por vezes, ainda se enfoca o ensino para um aluno-trabalhador, com o intuito de torná-lo um mero "empregável" disponível no mercado, e se deixa de lado o olhar sobre o alunocidadão. Por consequência, com base em nossa percepção do contexto, identificamos que as aulas de Inglês ou Inglês Instrumental acabam se voltando mais para questões linguísticas, visando ao preparo para concursos, ou focando no desenvolvimento de habilidades de leitura para aplicação em textos da área técnica específica de estudo.

Abordar aspectos linguísticos e desenvolver habilidades de leitura são, de fato, elementos importantes e necessários ao ensino de línguas, especialmente do Inglês. Porém, acreditamos que a Educação Profissional e Tecnológica, ainda que forneça aos discentes a capacitação em uma área técnica, precisa, também, ser um canal de desenvolvimento de suas habilidades como cidadãos, a fim de que formemos sujeitos autônomos, pensantes, capazes de agir efetivamente na sociedade.

Diante desse cenário, evidencia-se ser de extrema necessidade repensar o ensino de Inglês nas instituições federais, considerando que o ensino da língua vai muito além de 
conteúdos gramaticais. Assim, partilhamos do pensamento de estudiosos como Frigotto (2001) e Gadotti (2012) e defendemos que o ensino de todas as disciplinas deve colaborar para o desenvolvimento integral dos alunos, a fim de que sejam autônomos em sua totalidade. Em outras palavras, a educação deve se dar sob um viés emancipatório, desenvolvendo o pensamento crítico dos indivíduos e capacitando-os a transformar a realidade em que se inserem (cf. GADOTTI, 2012).

A importância de adotar uma abordagem de ensino de línguas que parta de um viés emancipatório encontra-se na sua capacidade de contribuir para "a reconstrução de identidades, subjetividades, narrativas, relações de poder e realidades na esfera social aliada ao trabalho de exploração do texto" (TAKAKI, 2012, p. 984). Por meio de uma percepção crítica, é possível ensinar não só a língua no âmbito do código linguístico, mas propiciar a análise de questões essenciais à vivência dos estudantes como cidadãos do mundo por meio do uso e funcionamento da(s) língua(s) no cotidiano.

Nesse sentido, este artigo apresenta resultados obtidos a partir da abordagem de questões étnico-raciais em aulas de duas turmas de Inglês Instrumental do curso técnico em Administração na modalidade concomitante/subsequente, em um campus em implantação do IFRJ, na região metropolitana do Rio de Janeiro, no ano de 2018. Para a discussão da temática proposta, as docentes envolvidas no projeto desenvolveram uma unidade didática que conciliava o debate em torno da celebração da Consciência Negra no Brasil e a implementação do uso de novas tecnologias em sala de aula, fugindo de um ensino tradicional e tecnicista.

Os resultados a serem comentados nas seções a seguir, obtidos a partir da efetivação de uma abordagem crítica de ensino de Inglês (cf. TILIO, 2017) e da aproximação dos discentes com as novas tecnologias, apontam que as ferramentas tecnológicas precisam estar mais presentes na formação dos estudantes de cursos técnicos, associadas à adoção de uma perspectiva emancipatória, para que se possa, cada vez mais, promover um maior engajamento e a consequente autonomia dos alunos, visto que esse aprendizado se torna mais significativo. Além disso, apresentaremos, neste trabalho, nossas reflexões acerca dos benefícios alcançados por meio da promoção dos multiletramentos (cf. ROJO; MOURA, 2012; ROJO, 2013) de aprendizes ao refletirem sobre questões étnico-raciais não só no mercado de trabalho, mas na sociedade como um todo, possibilitando aos alunos serem mais autônomos (cf. FRIGOTTO, 2001; GADOTTI, 2012; OXFORD, 2003) e protagonistas de cidadania ativa.

\section{Por uma formação integral e transgressiva do indivíduo no ensino técnico por meio das NTICs}

Já estamos no século XXI e, portanto, as práticas docentes, juntamente com o devido investimento na educação pública, precisam acompanhar o progresso das Novas Tecnologias Digitais da Informação e da Comunicação (doravante NTICs). Sendo assim, acreditamos que a formação de cidadãos críticos e trabalhadores possa perpassar a inclusão digital de maneira que até aqueles que não possuem o devido acesso aos dispositivos (móveis ou não) possam aprimorar as suas práticas de letramento digital.

Desse modo, a capacitação para utilização de ferramentas digitais e seu uso propriamente dito em sala de aula são fatores essenciais para que a escola garanta a participação ativa dos discentes como cidadãos do mundo em que vivem. Segundo 
Brydon (2009 apud MATTOS, 2011, p. 199), cidadania significa "ser capaz de participar" e, para isso, é necessário que os indivíduos tenham habilidades específicas, especialmente aquelas relacionadas aos multiletramentos. É preciso considerar que estamos em uma era de rápida difusão das informações, via novas tecnologias. Assim, nossos alunos devem estar preparados para lidar com as novas ferramentas e saber utilizá-las de maneira crítica, a fim de serem capazes de entrar em contato com e compartilhar informações confiáveis, multimodais e de diferentes culturas. Nesse sentido, um ensino de línguas que se aproxime da Pedagogia dos Multiletramentos (ROJO; MOURA, 2012; ROJO, 2013, entre outros) se mostra benéfico para os estudantes, visto que tem como princípio norteador o trabalho com a multiplicidade de linguagens e culturas.

Concordamos com Vetromille-Castro (2019) no que tange ao ensino e aprendizagem de línguas ao buscarmos um ensino transgressivo, através da produção de materiais didáticos e do desenvolvimento de práticas pedagógicas, juntamente com as tecnologias digitais, que são pautadas "pelas demandas sociais e pelos princípios educacionais, e não por pressões mercadológicas sem bases teórico-metodológicas consagradas pela ciência" (VETROMILLE-CASTRO, 2019, p. 206). Conforme já mencionamos, a formação dos estudantes da rede técnica federal deve ter como objetivo trabalhar a integralidade de sua formação cidadã. Acreditamos, portanto, que a educação deva ser abordada sob uma perspectiva emancipatória, buscando propiciar aos educandos a autonomia social, econômica e política. Para tal, é necessário que priorizemos, em sala de aula, o desenvolvimento da capacidade de os alunos pensarem a realidade e de promoverem a justiça e a solidariedade (cf. FRIGOTTO, 2001; GADOTTI, 2012, entre outros).

A educação sob uma perspectiva emancipatória concebe o professor como intelectual transformador, ou seja, alguém que seja capaz de utilizar todo o seu conhecimento adquirido, por meio dos estudos e da pesquisa, a fim de auxiliar na transformação da realidade social em que está inserido. Além disso, a escola é vista como espaço de contestação e construção de uma visão crítica da sociedade. Dessa forma, a escola precisa ser um ambiente que tenha como pilares de sustentação a democracia, a liberdade de expressão e a busca pela igualdade (social, racial, de gênero etc.). Nos apoiamos em Freire (1996) e concordamos que, dentre outros fatores, ensinar:

Quadro 1 - Aspectos da Pedagogia da Autonomia

\begin{tabular}{|l|}
\hline a) exige respeito aos saberes dos educandos; \\
\hline b) exige criticidade; \\
\hline c) exige risco, aceitação do novo e rejeição a qualquer forma de discriminação; \\
\hline d) exige reflexão crítica sobre a prática; \\
\hline e) exige a convicção de que a mudança é possível; \\
\hline f) exige compreender que a educação é uma forma de intervenção no mundo. \\
\hline
\end{tabular}

Fonte: Freire (1996), elaborado pelas autoras.

Com base nos pressupostos de Paulo Freire, entendemos que o ensino de língua inglesa possa percorrer um caminho de não valorização exacerbada de uma cultura hegemônica e tampouco de uma abordagem que privilegie o status quo, diferentemente do que é comumente realizado em instituições - especialmente privadas - de ensino. Encontramos, com frequência, nas diferentes mídias (televisão, YouTube, Facebook, 
entre outros), a venda de cursos de idiomas, principalmente de língua inglesa, que destacam as variantes mais prestigiadas, como o inglês americano e o britânico, além de priorizarem o ensino vindo de "professores americanos", como é o caso da Open English (cf. D'ALMAS, 2016). Diante desse cenário, fazemos coro com VetromilleCastro (2019) no que diz respeito ao entendimento do que seria "ensinar" uma língua, reconhecendo que esse processo não corresponde à "transmissão de saberes", mas engloba a construção dos seres, a partir das interações com os outros.

A perspectiva teórica adotada nesta pesquisa envolve o oposto do que é praticado por cursos de idiomas como aquele anteriormente citado. A presente pesquisa situa-se em um campus do IFRJ, em um curso técnico em Administração que possui caráter gratuito, tendo como público-alvo majoritariamente a classe trabalhadora, que, em boa parte, não teria condições de pagar um curso privado ou não teria recursos tecnológicos para cursar on-line. Nesse contexto, defendemos que o ensino de língua inglesa instrumental em escolas, especialmente, em cursos técnicos, embora seja muito relacionado ao ensino de leitura, pode ir além do ensino do mono skill, isto é, pode se dar a partir da compreensão de que ensinar uma língua deve considerar o contexto sóciohistórico dos estudantes e dos gêneros discursivos utilizados em sala de aula (cf. ONODERA, 2015; ROSSINI; BELMONTE, 2015, entre outros).

Sendo assim, devemos buscar refletir e reformular os currículos e práticas pedagógicas de ensino de língua inglesa que ainda não contemplem os temas cruciais para a formação crítica (cf. TILIO, 2017), transgressiva (cf. PENNYCOOK, 2006; HOOKS, 2017; VETROMILLE-CASTRO, 2019, entre outros) e integral (cf. FRIGOTTO, 2001; GADOTTI, 2012, entre outros) dos estudantes, incluindo as diferenças socioculturais, a partir do "ensino de linguagem por meio do seu uso próprio" (TILIO, 2018, p. 266). A partir dessas perspectivas, acreditamos que é possível contribuirmos para a formação mais autônoma dos estudantes, ao considerar a linguagem como instrumento de mediação das interações sociais (cf. OXFORD, 2003).

Com base nesses pressupostos, a próxima seção tratará especificamente das questões étnico-raciais trabalhadas em conjunto com o desenvolvimento dos multiletramentos, a fim de trazer à reflexão elementos de desigualdade racial no contexto brasileiro.

\section{As questões étnico-raciais e os multiletramentos no ensino}

O Ministério do Desenvolvimento Social ${ }^{2}$ (BRASIL, 2018), através do documento "SUAS Sem Racismo - Promoção da Igualdade Racial no Sistema Único de Assistência Social", fez um alerta sobre os casos de racismo no mercado de trabalho e dos índices de desigualdade racial no Brasil. Com dados coletados do Sistema de Informações do Serviço de Convivência e Fortalecimento de Vínculos (SISC), de 2018, o documento nos explica que

\footnotetext{
${ }^{1}$ Deduzimos que o curso Open English valoriza os estadunidenses, em detrimento dos professores de outros países da América do Sul e Central (cf. VETROMILLE-CASTRO, 2019).

2 O Ministério do Desenvolvimento Social foi extinto e, atualmente, se constitui de Secretaria Especial do Desenvolvimento Social, pertencente ao Ministério da Cidadania. Fonte: https://desenvolvimentosocial.gov.br/. Acesso em 22 de mar. 2020.
} 
quando falamos de vivência de violência e/ou negligência, $70,8 \%$ são pessoas pretas e pardas e $28 \%$ brancas. Em situação de abuso e/ou exploração sexual, $68,6 \%$ dos participantes do serviço são pretos e pardos e $29,8 \%$ são brancos. Já quanto às crianças e adolescentes em situação de rua, $77,9 \%$ são pretos e pardos e $20,7 \%$ são brancos.

As mulheres negras são as que permanecem enfrentando as maiores barreiras de inserção no mercado formal de trabalho e de reconhecimento do valor de seu trabalho. São as que têm a menor remuneração quando comparado aos salários de homens e mulheres brancas e de homens negros (DIEESE. Os negros nos mercados de trabalho metropolitanos. Pesquisa de emprego e desemprego - PED) (BRASIL, 2018, p. 6).

A partir desses dados, é necessário, no ensino de língua inglesa instrumental, uma abordagem que incentive o debate e promova a formação crítica de futuros técnicos em Administração, em um passo em direção a uma educação menos tecnicista (cf. GADOTTI, 2012) e com o caráter mais transformador (cf. FREIRE, 2019 [1968]; MIZAN, 2018, entre outros). Assim, poderemos contribuir para a inserção, no mercado de trabalho, de profissionais da área administrativa que sejam conscientes dos seus papéis na sociedade e atentos às relações de poder existentes que, infelizmente, contribuem para a manutenção dos casos de racismo no Brasil.

Ainda temos muito a fazer para inserir, em grande escala, a abordagem de questões étnico-raciais no ensino de língua inglesa instrumental no nosso país, apesar de já existirem iniciativas que busquem contemplar essa diversidade sociocultural (cf. LINS at al., 2016). Silva afirma que

a escola é um espaço em que os valores eurocêntricos são difundidos e privilegiados, em detrimentos de outras culturas (...). O material didático está repleto de conteúdos depreciativos e preconceituosos em relação aos negros e povos indígenas, o que pode contribuir para o fracasso escolar dos alunos pertencentes a esses grupos (SILVA, 2018, p. 132).

Vale ressaltar que os cursos técnicos, no Brasil, não se enquadram na categoria de Educação Básica, portanto, não há a participação no Programa Nacional do Livro Didático $(\mathrm{PNLD})^{3}$. Geralmente, os materiais didáticos, especialmente os de língua inglesa, são elaborados pelos próprios professores e levam em consideração a proposta do curso, o perfil e as necessidades dos estudantes. Nesse sentido, concordando com Onodera (2015), entendemos que "a análise de necessidades é um processo contínuo, sendo preciso reavaliar e reanalisar as necessidades" (ONODERA, 2015, p. 344).

Uma abordagem educacional emancipatória, como a que propõe Frigotto (2001), precisa buscar promover a igualdade (racial, social, de gênero etc.). Consequentemente, a discussão de questões étnico-raciais em sala de aula mostra-se de extrema importância em nosso contexto atual, em que presenciamos discursos negacionistas sobre os casos de discriminação racial no Brasil, por exemplo, conforme divulgado pela página do Instagram do Movimento Escola sem Partido (doravante ESP), em 30 de novembro de $2019^{4}$ :

\footnotetext{
${ }^{3}$ De acordo com o Portal do Ministério da Educação, o PNLD avalia e disponibiliza diferentes obras didáticas e literárias para as escolas públicas no Brasil. Fonte: https://bit.ly/3c9b5J3. Acesso em 06 de maio 2020.

${ }^{4}$ Publicação no Instagram @escolasempartidooficial, em 30/11/2019.
} 
Excerto 1: Investir desde cedo na mentira de que o Brasil é um país racista e homofóbico é uma forma dissimulada (sic passim) de valorizar os partidos que se apropriam dessas pautas, e de fabricar militantes para esses partidos ${ }^{5}$.

Enxergamos uma onda conservadora na sociedade brasileira, que ganhou força ao encontrar representação na figura do atual presidente Jair Messias Bolsonaro, desde a sua vitória nas eleições de 2018. Além disso, encontramos uma grande concentração de parlamentares com um forte viés religioso nas suas tomadas de decisões ${ }^{6}$, alguns alinhados ao ESP, que desconsideram ser relevante os debates acerca das questões de gêneros, raça, classe, entre outros, apresentando, conforme Oliveira e Mariz (2019, p.4), um discurso que defende o ensino de um "conhecimento asséptico e pasteurizado":

\begin{abstract}
Assim, pode-se dizer que, conquanto se apresente como um movimento neutro, sem ideologia, que busca apenas uma escolarização que proteja as famílias contra doutrinadores políticos e professores inescrupulosos, que corrompem a sexualidade e os valores morais dos estudantes, o Movimento Escola Sem Partido tem outras finalidades: a) cercear, nos espaços escolares, estudos e debates que questionem relações de poder e hierarquias que alicerçam as desigualdades sociais no Brasil e b) negar a alteridade e a diversidade como elementos inerentes à humanidade.
\end{abstract}

Diante desse contexto, fica ainda mais evidente a necessidade de trazermos para a sala de aula, nas palavras de Oliveira e Mariz (2019, p. 4), "debates que questionem relações de poder e hierarquias que alicerçam as desigualdades sociais no Brasil". Dessa forma, acreditamos que professores do ensino técnico da Rede Federal que defendam o caráter transformador da educação (cf. FREIRE, 2019 [1968]) possam levar tais questionamentos e debates para as aulas de línguas, inclusive as de Inglês Instrumental, com fins de fomentar a desconstrução de preconceitos e a valorização da diversidade.

Como um meio de buscar a valorização das diferentes culturas e linguagens na sociedade, bem como de promover um ensino de língua inglesa que contribua para uma maior participação dos estudantes nas esferas pública, econômica e em suas comunidades, nos aproximamos da Pedagogia dos Multiletramentos (cf. NEW LONDON GROUP, 2006 [1996]; COPE; KALANTZIS, 2009; ROJO; MOURA, 2012, entre outros) no curso técnico em Administração. Segundo Rojo (2013),

O conceito de multiletramentos, articulado pelo Grupo de Nova Londres, busca justamente apontar, já de saída, por meio do sufixo "multi”, para dois tipos de "múltiplos" que as práticas de letramento contemporâneas envolvem: por um lado, a multiplicidade de linguagens, semioses e mídias envolvidas na criação de significação para os textos multimodais contemporâneos e, por outro, a pluralidade e a diversidade cultural trazidas pelos autores/leitores contemporâneos a essa criação de significação (grifos da autora) (ROJO, 2013, p. 14).

Com base na Pedagogia dos Multiletramentos e buscando trazer os estudantes para o centro do processo de aprendizagem, a nossa proposta de ensino de Inglês

\footnotetext{
${ }^{5}$ Fonte: https://bit.ly/33KLXEX. Acesso em 23 de mar. 2020.

${ }^{6}$ As eleições de 2018 apontaram o aumento do número de parlamentares evangélicos ou ligados a outras esferas religiosas (bispos, cantores gospel, entre outros). Fonte: https://bit.ly/2WCjSga. Acesso em 27 de mar. 2020.
} 
Instrumental ancora-se na concepção de "lautor", isto é, considera os estudantes não apenas "leitores", mas também "autores" de novos textos multimodais. Preocupadas com a formação crítica e transgressiva de futuros técnicos em Administração, também acreditamos que promover o debate acerca de questões étnico-raciais pode estimular produções multimodais e multiculturais, nas quais se sobressaem as vozes dos estudantes sobre essa temática.

Assumimos como objetivo em nossa abordagem não apagar ou ignorar subjetividades nos debates realizados em sala de aula ou em espaços virtuais, como o Padlet, ferramenta digital a ser apresentada com mais detalhes na seção de metodologia. Além disso, também nos beneficiamos dos Estudos dos Novos Letramentos (cf. LANKHSEAR; KNOBEL, 2007), ao procurarmos trazer as novas tecnologias digitais para o ensino de língua inglesa, de forma que o conhecimento possa ser mais compartilhado e a aprendizagem mais colaborativa.

$\mathrm{Na}$ próxima seção, apresentamos a metodologia utilizada nesta pesquisa, bem como contextualizamos brevemente a nossa atuação docente em um campus em implantação do IFRJ.

\section{Metodologia de pesquisa}

A pesquisa aqui apresentada tem cunho qualitativo, visto que nosso foco se encontra no conteúdo gerado a partir das ações propostas, sem haver preocupação com índices numéricos. Buscamos trazer à discussão temas importantes para o ensino de língua inglesa com base em resultados obtidos por meio da análise de produções realizadas por alunos na plataforma Padlet $^{7}$ e de respostas a um questionário sobre o perfil desses estudantes, aplicado por meio do Google Forms, em novembro de 2018.

A escolha da plataforma Padlet justifica-se pela potencialidade de se trabalhar com recursos multimodais. Ao elaborar murais virtuais, o estudante pode lançar mão de imagens estáticas ou em movimento (videoclipes, gif $s^{8}$ ), textos escritos, músicas, entre outros. Somado a isso, a ferramenta também possibilita o incentivo à cooperação entre pares e o feedback do desenvolvimento dos trabalhos, através de comentários nos murais.

A aplicação do questionário que buscava traçar o perfil dos estudantes envolvidos na pesquisa deu-se pela necessidade de analisarmos aspectos como: faixa etária, nível de conhecimento linguístico e grau de aproximação com as novas tecnologias. Tais marcadores mostraram-se essenciais para a compreensão do conteúdo produzido pelos alunos e para nossa percepção quanto aos benefícios de promovermos os multiletramentos desses aprendizes. O quadro a seguir apresenta as principais respostas evidenciadas por meio do questionário disponibilizado aos discentes para o preenchimento entre os dias 6 e 13 de novembro de 2018:

\footnotetext{
${ }^{7}$ O Padlet é uma plataforma de criação de murais virtuais interativos e colaborativos e pode ser acessado tanto por computador, quanto por aplicativo em celular. Link: https://padlet.com. Acesso em 06 de mai. 2020.

${ }^{8}$ Segundo o site TechTudo, "GIF (Graphics Interchange Format ou formato de intercâmbio de gráficos) é um formato de imagem muito usado na Internet (...). Um tipo particular de GIF bastante conhecido é o chamado GIF animado. Ele na verdade é composto de várias imagens do formato GIF, compactadas em um só arquivo. Essa variante é utilizada para compactar objetos em jogos eletrônicos, para usar como emoticon em mensageiros instantâneos e para enfeitar sites na Internet". Disponível em https://glo.br/2VwpvwX. Acesso em 24 de abr. 2020.
} 
Quadro 2 - Principais respostas do questionário on-line de duas turmas do curso técnico concomitante/subsequente em Administração

\begin{tabular}{|c|c|}
\hline Número de respostas & 31 \\
\hline Faixa etária dos estudantes & Entre 16 e 49 anos \\
\hline Estudaram inglês antes do curso técnico & $83,3 \%$ \\
\hline $\begin{array}{l}\text { Tipo de material/ferramenta que mais } \\
\text { estudaram inglês }\end{array}$ & $41,4 \%$ responderam "livro didático" \\
\hline $\begin{array}{l}\text { Estratégias que utilizam para estudar } \\
\text { inglês }\end{array}$ & $\begin{array}{l}\text { - "Ver seriados, ouvir músicas e notícias } \\
\text { em inglês com legenda" } \\
\text { - "traduzir textos completos, assistir } \\
\text { series/ filmes com legenda, aplicativo } \\
\text { rosetta Stone" } \\
\text { - "Costumo escutar músicas" } \\
\text { - "Assisto filmes/séries em inglês } \\
\text { (legendado), escuta músicas em inglês e } \\
\text { acompanho a letra" }\end{array}$ \\
\hline
\end{tabular}

Fonte: Elaborado pelas autoras

Anteriormente à fase de produção dos murais virtuais, as docentes aplicaram o referido questionário e executaram, em duas turmas que estavam sob sua responsabilidade, no curso técnico em Administração concomitante/subsequente ao Ensino Médio em um campus do IFRJ, uma unidade didática que focava na discussão de questões étnico-raciais na sociedade. A execução dessa unidade didática ocorreu no mês de novembro, mês de celebração da Consciência Negra no Brasil. Por meio das atividades propostas, os alunos puderam discutir, trocar ideias e ter acesso a diferentes informações acerca do tema. Por questões de espaço, vamos nos ater, neste artigo, à breve análise do perfil desses estudantes e das produções geradas por eles na plataforma Padlet.

Depois de aplicada a unidade didática, as professoras conduziram os alunos ao Laboratório de Informática ${ }^{9}$, cada turma em seu respectivo horário de aula, onde puderam acessar a plataforma Padlet e montar seus murais interativos com base em temáticas étnico-raciais. Os murais, depois de montados, eram compartilhados com os demais colegas, que poderiam fazer comentários acerca das postagens. Essas atividades ocorreram como parte da disciplina de Inglês Instrumental, que é ofertada no primeiro período do curso técnico em Administração.

Os alunos da Turma A, por serem um grupo com menor quantidade de estudantes, puderam elaborar os murais individualmente nos computadores do Laboratório de Informática. Já os alunos da Turma B realizaram a tarefa em duplas ou em trios, devido à quantidade de computadores disponibilizada.

Mostraremos, na seção a seguir, algumas dessas produções e analisaremos os benefícios gerados para a aula de Inglês Instrumental em um curso técnico.

\footnotetext{
9 Embora exista a versão em aplicativo da plataforma, nem todos os estudantes possuíam smartphones ou a devida conexão à Internet para acessá-lo. Assim, preferiu-se utilizar a versão desktop, no Laboratório de Informática do campus.
} 


\section{Análise de dados}

Os dados desta pesquisa foram gerados no mês de novembro de 2018. Por se tratar de um curso técnico, o público-alvo das turmas envolvidas era constituído majoritariamente de adultos. Acreditamos que o fato de o curso ser no turno da noite possa ter contribuído para a inclusão dessa faixa etária, composta, em sua maior parte, pela classe trabalhadora.

As informações obtidas por meio do questionário on-line disponibilizado para preenchimento dos alunos e previamente detalhado na seção de metodologia indicam, principalmente, a heterogeneidade etária do corpo discente nesse curso, visto que a faixa etária dos estudantes variava entre 16 e 49 anos.

Identificamos, também, que a maioria dos estudantes já havia estudado inglês em algum momento da vida. Embora os dados apontem o uso majoritário de livros didáticos para aprender inglês, os comentários sobre as estratégias de estudo, de uma parte dos estudantes, apontam para a aproximação com algumas tecnologias digitais e multimodais, tais como assistir a séries e a filmes. Destacamos, também, a importância da música como contato com a língua inglesa por esses aprendizes.

Outro dado importante que ressaltamos é a falta de familiaridade com a ferramenta Padlet, com a qual apenas um estudante já tinha tido algum tipo de experiência; no entanto, não temos a informação sobre a forma como este conhecimento foi adquirido. O pouco conhecimento acerca dessa plataforma nos leva a acreditar que fazer uso dela no ensino de língua inglesa seja fundamental para incentivar os discentes a utilizarem novas ferramentas digitais que possibilitem a edição e o compartilhamento de textos multimodais.

Antes de partirmos para a análise das produções multimodais dos estudantes das turmas investigadas, apresentamos, brevemente, alguns aspectos abordados nas unidades didáticas elaboradas pelas professoras das turmas e que antecederam o trabalho desenvolvido na plataforma Padlet, segundo o quadro 3:

Quadro 3 - Principais elementos presentes nas unidades didáticas

\begin{tabular}{|c|c|c|c|}
\hline Turma & Tema(s) & Gêneros discursivos & Aspectos léxico-gramaticais \\
\hline A & $\begin{array}{c}\text { Segregação racial } \\
\text { nos EUA e Dia da } \\
\text { Consciência Negra } \\
\text { no Brasil }\end{array}$ & Notícias & Phrasal Verbs e Simple Past \\
\hline B & $\begin{array}{c}\text { A vida de Martin } \\
\text { Luther King Jr e } \\
\text { de Conceição } \\
\text { Evaristo }\end{array}$ & Biografias curtas & Simple Past \\
& & \\
\hline
\end{tabular}

Fonte: Elaborado pelas autoras

As docentes abordaram temas que possibilitaram o debate acerca de questões étnico-raciais em sala de aula. Cabe ressaltar, ainda, que, por mais que tenham sido trabalhados temas propiciadores de debate, não foram deixados de lado os aspectos léxico-gramaticais da língua, que também consideramos importantes para o aprendizado. Vale notar que o ensino por um viés emancipatório não abandona os conteúdos formais 
pertinentes às disciplinas, mas os trabalha com base em e a partir de temáticas que perpassem a vivência dos alunos como cidadãos.

Após o trabalho em sala de aula com os temas e gêneros anteriormente apresentados, cada professora seguiu com a sua respectiva turma para o Laboratório de Informática para procederem à elaboração de murais virtuais. A fim de inspirar os alunos em suas produções, as docentes apresentaram um mural virtual por elas elaborado na plataforma Padlet $^{10}$. A personalidade homenageada foi Martin Luther King Jr, líder do movimento contra a segregação racial nos Estados Unidos. Para a construção desse mural virtual, foram utilizados gifs, um texto biográfico e um link que dá acesso a um vídeo do YouTube sobre o discurso I Have a Dream, proferido pelo ativista em 28 de agosto de 1968, na Marcha sobre Washington, conforme podemos observar a seguir:

Figura 1: Mural virtual sobre Martin Luther King Jr

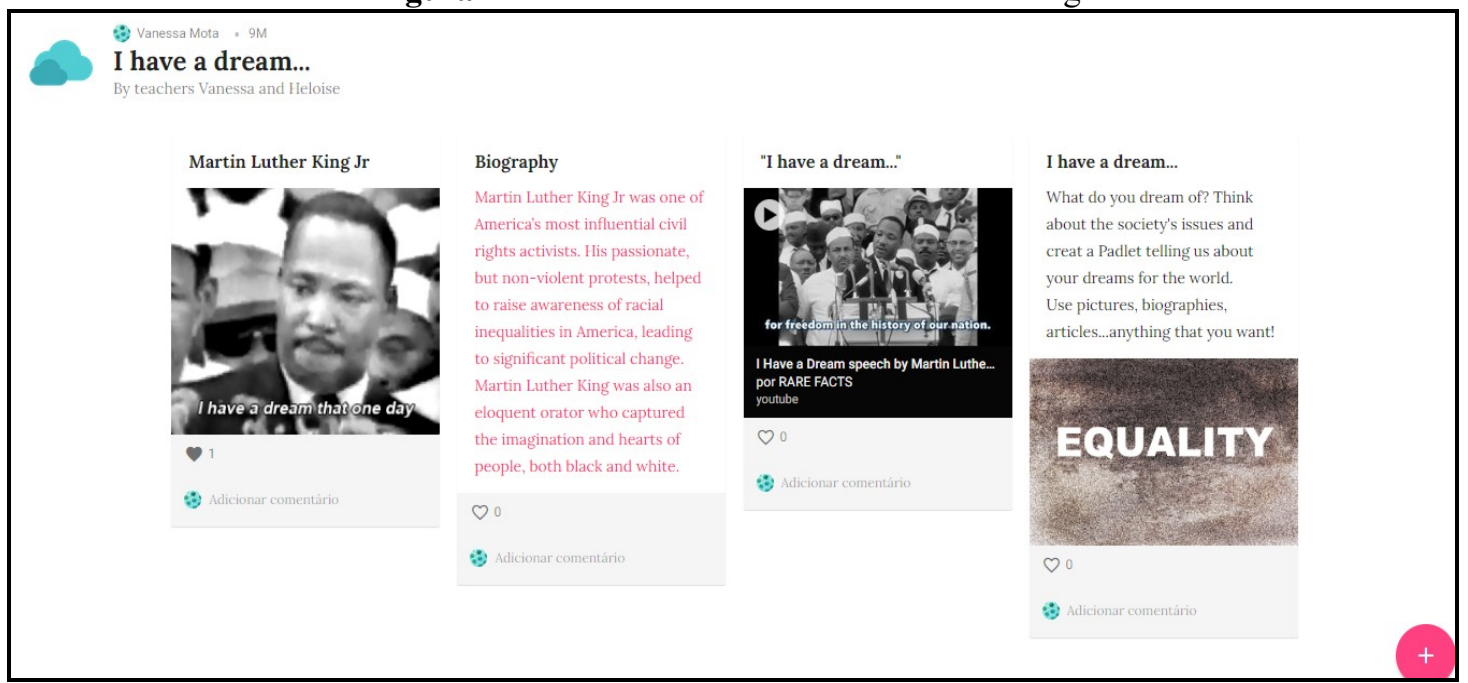

Fonte: Padlet elaborado pelas professoras das turmas

Passaremos, agora, à análise das produções dos alunos a partir da proposta das professoras. Por restrições de espaço, não abordaremos todos os murais elaborados pelos estudantes por completo, mas daremos foco a algumas mensagens (fotos/vídeos/comentários) compartilhadas por eles.

$\mathrm{O}$ primeiro trecho a ser analisado refere-se à criação de uma estudante da Turma A, Dandara ${ }^{11}$ (ver Fig. 2). Em seu mural, a estudante, na época com 28 anos e assistente social, compartilhou um videoclipe do cantor brasileiro Criolo intitulado "Boca de Lobo" $"$. Destacamos que esse clipe possui referências a questões político-sociais pertinentes à realidade brasileira e, mesmo sendo em língua portuguesa, acreditamos estar tematicamente relacionado com a unidade didática de inglês, que tratou sobre a questão da desigualdade racial no mundo.

Algumas dessas referências que podemos identificar no vídeo são: as riquezas de políticos, oriundas de corrupção $^{13}$; o desastre do rompimento da barragem do

10 Link de acesso: https://padlet.com/vanessammota/ihaveadream2018. Acesso em 22 de mar. 2020. 11 Todos os nomes utilizados neste artigo são fictícios, a fim de preservar a identidade dos participantes. 12 Link para acesso: https://www.youtube.com/watch?v=jgekT-PEb6c. Acesso em 27 de mar. 2020. 13 Fonte: https://bit.ly/39qET1E. Acesso em 27 de mar. 2020. 
Fundão, em Mariana, ocorrido em 2015, que deixou 19 mortos $^{14}$; e a figura da Marielle Franco, vereadora do Rio de Janeiro assassinada em 2018, representada por uma mulher que se destaca em uma cena de caos.

A referida postagem no mural da Dandara evidencia a persistência das desigualdades na sociedade brasileira e dialoga diretamente com os debates previamente realizados em sala. Após a elaboração dos Padlets, os colegas deveriam analisar as produções da outra turma e tecer comentários. Sendo assim, os comentários proferidos por Tiana (professora, 26 anos) e Rubens ${ }^{15}$ (sem informações pessoais) demonstram apreciação pela música escolhida por Dandara, através dos comentários "brabo" (Rubens) e "Amoo!!" (Tiana). Acreditamos que o efeito causado pela identificação com aquilo que se gosta seja bastante benéfico para promover a motivação e a consequente autonomia dos estudantes.

Figura 2: Print de parte do mural virtual da aluna Dandara (Turma A)

Fonte: Padlet criado pela Turma A

Identificamos, língua portuguesa nas e entendemos que isto baixa proficiência em língua inglesa, bem como com o repertório cultural dos estudantes aluna Dandara, da

pois, a presença da produções discentes se alinha com sua

14 Fonte: https://brasil.elpais.com/brasil/2019/01/25/politica/1548443780_104893.html. Acesso em 27 de mar. 2020.

${ }^{15} \mathrm{O}$ estudante não preencheu o questionário. 
de associarem as temáticas trabalhadas em sala de aula com a cultura brasileira. Destacamos que não corrigimos e nem repreendemos os alunos pelo uso da sua língua materna, numa forma de evitar constrangimentos e diminuição da sua autonomia na elaboração dos Padlets.

A próxima imagem (Fig. 3) é o recorte de um mural da Turma B. Apesar de as Fig. 2 e 3 apresentarem produções de grupos oriundos de turmas distintas, podemos aproximar o conteúdo apresentado nelas através das referências a Marielle Franco.

$\mathrm{Na}$ Fig. 3, podemos ver que a estudante Bia, de 32 anos, compartilhou um vídeo retirado do YouTube sobre uma homenagem à Franco. O vídeo faz parte da conta "Analfabeto Político" e, diferentemente do que o nome indica, o canal "é um programa que quer tratar a política de uma forma mais leve nestes tempos de ânimos acirrados." 16

A descrição do vídeo intitulado "Marielle, presente! Agora e sempre!", traduzido para o inglês pela aluna como "MARIELLE, PRESENT! NOW AND EVER", indica que se trata de uma homenagem à vereadora através de uma canção nas vozes de 24 cantoras, entre elas Zezé Motta, Teresa Cristina, Olivia Hime, Ana Costa e Dorina. Ainda, salientamos que um trecho da música estabelece uma relação de intertextualidade com o Hino Nacional Brasileiro ${ }^{17}$, apontando que aqueles que a seguiam não iriam fugir à luta pela justiça social: "Teus filhos não fogem à luta/A bala não cala a fala/E nem mata o amor/Teu nome no muro/É a morte do algoz/Sob o poder do sol"18.

Figura 3: Print de parte do mural virtual do Grupo 1 (Turma B)

Fonte: Padlet Bia, da Turma B

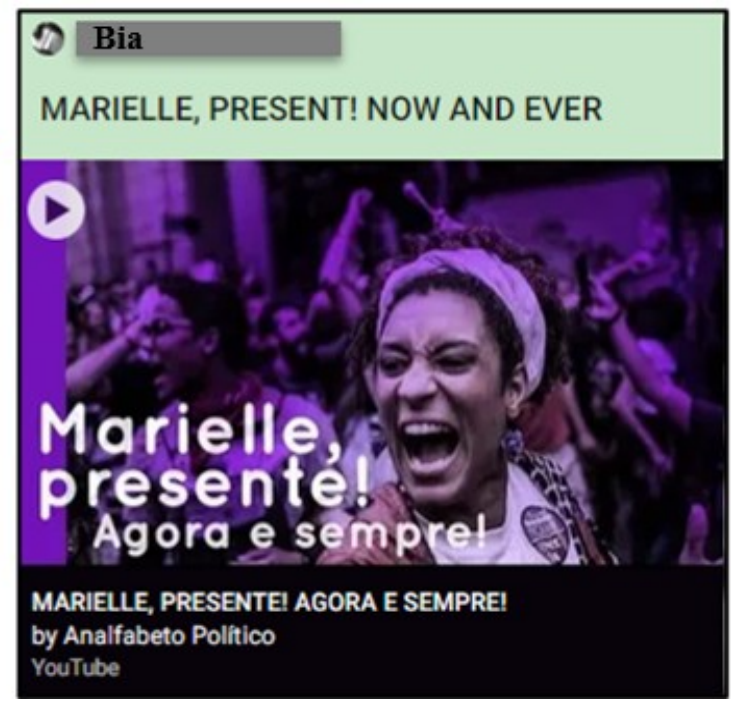

elaborado pela aluna

Apresentamos, a seguir, outra produção que nos chamou bastante a atenção. A criação dos alunos engloba predominantemente imagens intituladas por meio de palavras em inglês que resumiam seu significado (ver Fig. 4). Este mural, diferentemente das imagens anteriores, será analisado em sua totalidade, visto que a sua configuração requer um olhar pelo todo e a sua análise fracionada prejudicaria o seu entendimento.

16 Fonte: https://bit.ly/2VxXxRv. Acesso em 24 de abr. 2020.

17 Fonte: https://bit.ly/2S3hkGp. Acesso em 24 de abr. 2020.

18 Disponível em: https://www.youtube.com/watch?v=rf-Ke4JKfiI. Acesso em 13 de abr. 2020. 
Figura 4: Print do mural virtual do Grupo 2 (Turma B)

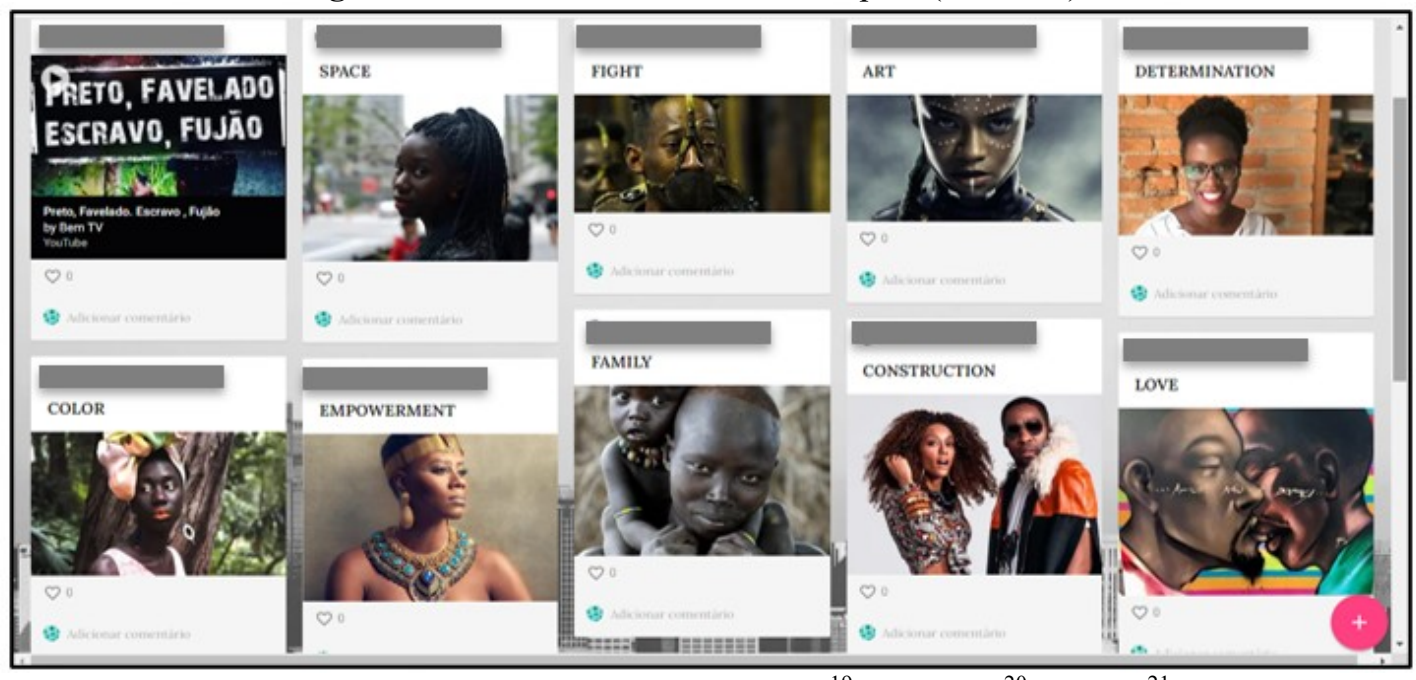

Fonte: Padlet elaborado pelos alunos Valter ${ }^{19}$, Fernanda $^{20}$ e Felipe ${ }^{21}$

O grupo parece ter se preocupado em abordar temáticas pertinentes à luta contra a desigualdade racial ao selecionar imagens protagonizadas por pessoas negras, representando diferentes frentes de luta. Assim, podemos identificar categorias como: space (espaço), fight (luta), art (arte), family (família), love (amor).

No que tange à categoria space ${ }^{22}$, é possível observar a imagem de uma mulher negra em meio a um cenário urbano. A representação feita por meio da imagem escolhida pelos estudantes parece indicar ao leitor de seu mural virtual a ideia de que mulheres negras podem conquistar os espaços que quiserem, como quiserem.

$\mathrm{Na}$ categoria fight, há a imagem de uma pessoa negra acorrentada e amordaçada. Percebemos a referência direta ao processo de escravização sofrido pelo povo africano e seus descendentes ao longo da colonização de países ao redor do mundo.

Quanto ao ponto art, indicado pelo grupo em seu mural, foi utilizada a imagem de uma atriz negra, Letitia Wright, que se destacou pelo seu papel no filme Pantera Negra, da Marvel Comics. Essa obra, lançada no ano de 2018, conta a história do príncipe do reino de Wakanda - nação superdesenvolvida constituída de membros de povos africanos e que é referência no uso de alta tecnologia - e seu encontro com os Vingadores, grupo de super-heróis americanos majoritariamente brancos. O longametragem foi predominantemente encenado por atores negros e trouxe à discussão o tema da representatividade negra no cinema.

A categoria love foi representada pelos alunos por meio da imagem de um casal negro homoafetivo. A escolha dessa ilustração para representar a referida categoria nos traz a reflexão acerca do preconceito envolto na temática de gênero e orientação sexual.

\footnotetext{
${ }^{19}$ Valter, 19 anos e atendente.

${ }^{20}$ Fernanda, 29 anos, auxiliar de escritório.

${ }^{21}$ Felipe, 19 anos, estudante.

${ }^{22}$ Como o grupo não utilizou muita linguagem verbal em seu mural, realizamos a interpretação dos dados apresentados com base em nossa leitura e pautadas em nossa vivência e conhecimento de mundo. Reconhecemos, portanto, que aspectos distintos podem ser percebidos pelos diferentes leitores que tiverem acesso ao referido mural.
} 
À primeira vista, o mural apresentado na Fig. 4 pode parecer simples e básico; no entanto, traz à luz temáticas de extrema importância para a formação dos alunos como cidadãos. Ao serem evidenciados temas como amor, luta e arte, que perpassam a vida de todos os estudantes, estamos colocando em prática uma perspectiva emancipatória de ensino, que vai além da explanação de conteúdos formais, possibilitando, nas palavras de Gadotti (2012), a concretização de processos educativos "comprometidos com uma visão de mundo transformadora, inconformada com um mundo injusto e insustentável em que vivemos" (GADOTTI, 2012, p. 2).

Vale salientar que o mural em foco foi construído por um grupo que possuía um aluno negro e, portanto, as temáticas trabalhadas em sala e enfocadas em sua produção fazem parte de sua vida diária. Segundo a concepção emancipatória de educação, esta deve partir e ser voltada para a trajetória de vida dos alunos, buscando contemplar suas necessidades específicas ao invés de se sujeitar aos ditames do mercado.

Conforme fica evidente, o recurso disponibilizado pelo Padlet funciona mais como um reduto de informações, um compilado de textos multimodais que propiciam ao leitor um acesso panorâmico ao tema proposto. Para tanto, o criador do mural virtual precisa realizar ampla pesquisa para inserir os itens a serem expostos.

No caso da atividade proposta pelas autoras, além do debate e atividade prévia em sala, os alunos fizeram pesquisas e buscas na internet por textos que fossem pertinentes à temática em foco e que pudessem acrescentar significativamente à construção de seu mural virtual. Essa pesquisa foi feita individualmente ou em grupo, no laboratório de informática do campus, sem interferência das professoras. Sendo assim, os alunos assumiram papel central na construção do conhecimento ao longo da produção dos materiais digitais, bem como foram estimulados a acessar os conteúdos produzidos pelos grupos de outras turmas e a interagirem com eles (ver Fig. 2), o que aponta para um passo rumo à uma educação que promova a autonomia sociocultural (cf. OXFORD, 2003).

Do ponto de vista do leitor dos murais virtuais, este tem contato com materiais diversos, propiciando uma visão ampla acerca de um tema. Desse modo, com base em sua vivência e conhecimento de mundo, por meio do que pôde inferir e depreender dos conteúdos apresentados nos murais, o leitor constrói seu próprio significado acerca do tema. Essa produção individual de significado também evidencia a promoção da autonomia no processo de ensino e aprendizagem.

Diante dos pontos analisados a partir das produções dos alunos na plataforma Padlet, fica evidente a necessidade e importância de se abordarem temáticas que perpassem a vivência dos discentes como cidadãos, colaborando para seu maior engajamento. Os alunos de ambas turmas participaram ativamente de todo o processo e se mostraram interessados em discutir, em sala, temáticas que fazem parte de sua vida como indivíduos. Além disso, ficou visível que a aproximação com o uso de ferramentas digitais em sala de aula contribuiu para a promoção da autonomia, colocando os alunos como protagonistas no processo de ensino e aprendizagem.

\section{Considerações finais}

Com base na experiência de atividade relatada neste artigo, identificamos que a ferramenta Padlet consiste em um espaço virtual para o compartilhamento não só de textos multimodais em inglês, mas também de posicionamentos políticos voluntários dos 
estudantes. Essa possibilidade tornou-se evidente por meio da abordagem crítica de aspectos sociais relevantes e pertinentes à vida dos discentes e sua participação na sociedade: as questões étnico-raciais (cf. SILVA, 2018). A mudança na dinâmica de participação e interação dos alunos em sala de aula adotada pelas docentes não só contraria a onda conservadora que visa silenciar o debate sociopolítico nos espaços educacionais, mas também contribui para a promoção de práticas de cidadania ativa.

As produções multimodais dos estudantes mostraram-se em diálogo com as questões sociopolíticas vigentes no Brasil no ano de 2018, ao serem compartilhados conteúdos que faziam referência à vereadora assassinada naquele mesmo ano, Marielle Franco (Fig. 2 e 3). Tal fato nos aproxima de uma educação que não esteja dissociada das práticas sociais dos estudantes e que aborde as "culturas de referência do alunado (popular, local, de massa) e de gênero, mídias e linguagens por ele conhecidos, para buscar um enfoque crítico, pluralista, ético e democrático" (ROJO; MOURA, 2012, p. 8).

Quanto ao papel do professor em meio à experiência relatada neste artigo, constatamos que adotar a postura de intelectual transformador (cf. GADOTTI, 2012) faz diferença para a promoção da educação em uma perspectiva emancipatória. Percebemos que os conhecimentos adquiridos pelas professoras ao longo de suas trajetórias de pesquisa e ensino possibilitaram a elas rever, reavaliar e reformular a dinâmica de suas aulas. Assim, foi possível colocar em prática uma proposta de atividade que partia das experiências de vida dos alunos e que visava desenvolver suas habilidades de multiletramentos.

Diante do exposto até então, torna-se notória a importância de adotarmos uma concepção de educação sob um viés transgressivo (cf. HOOKS, 2017). Em meio a um cenário de precariedade de materiais didáticos que abordassem questões pertinentes à realidade social dos alunos, transgredir tornou-se a alternativa mais apropriada a fim de que pudéssemos, de fato, promover um ensino integral e emancipatório de nossos alunos, capacitando-os para o exercício da cidadania.

Como aspectos a serem melhor trabalhados, destacamos a necessidade de se desenvolverem as habilidades de produção em língua inglesa por parte dos estudantes. Conforme pudemos observar nos trechos de murais analisados, algumas produções ocorreram em língua portuguesa. Em outros casos, percebemos o uso da língua inglesa de maneira bastante "tímida", apresentando poucas palavras na língua-alvo.

Apesar disso, acreditamos que a introdução das novas tecnologias (cf. LANKSHEAR; KNOBEL, 2007) e o trabalho baseado nos multiletramentos (cf. COPE; KALANTZIS, 2009) têm muito a contribuir para o debate, no ensino de inglês, sobre as questões étnico-raciais e outras temáticas pertinentes à trajetória de vida dos alunos, ao valorizar a multiplicidade de linguagens existentes em espaços virtuais, que podem servir como meios de difusão das culturas do alunado, em busca da promoção da autonomia (OXFORD, 2003).

Como perspectivas futuras, apontamos a necessidade do desenvolvimento contínuo de um projeto que trate da pesquisa segura na internet e da netiqueta, isto é, a etiqueta na Internet, em parceria com outras disciplinas, visto que isso pode contribuir para a formação dos futuros técnicos em Administração que, certamente, deverão ter conhecimentos avançados sobre o uso de novas tecnologias digitais na atuação profissional. Dessa forma, destacamos que não só a disciplina de Inglês, mas o curso Técnico Concomitante/Subsequente em Administração, como um todo, precisa 
promover, de forma interdisciplinar, o debate acerca das diferentes desigualdades existentes na sociedade.

\section{Referências}

BENDER, A. B. Inglês na Educação Profissional e Tecnológica: integrando temáticas da área técnica a competências linguísticas. Dissertação (Mestrado Profissional em Educação Profissional e Tecnológica). Instituto Federal de Santa Catarina, Centro de Referência em Formação e Educação à Distância - CERFEAD. Departamento de Educação à Distância. Florianópolis, SC, 2019.

BRASIL. Ministério do Desenvolvimento Social (MDS). SUAS sem racismo promoção da igualdade racial no Sistema Único de Assistência Social. Disponível em: https://bit.ly/35z08Od. Acesso em 04 de maio de 2020.

COELHO, H. S. H. "É possível aprender inglês na escola?" Crenças de professores e alunos sobre o ensino de inglês em escolas públicas. Dissertação (mestrado) - Programa de Pós-Graduação em Estudos Linguísticos, Faculdade de Letras, Universidade Federal de Minas Gerais. 2005.

COPE, B.; KALANTZIS, M. Multiliteracies: New Literacies, New Learning. Pedagogies: an international journal, v. 4, Issue 3, 2009. Disponível em: http://newlearningonline.com/files/2009/03/m-litspaper13apr08.pdf. Acesso em 24 de jan. 2017.

D’ALMAS, J. Mídia e identidade do professor de língua inglesa: uma análise do discurso crítica de propagandas de um curso de inglês online. 2016. Disponível em: https://bit.ly/2yjlD9V. Acesso em 23 de mar. 2020.

DANTAS, S. G. M. As crenças dos professores em inglês instrumental nos cursos de ensino médio técnico integrado no IFRN. Revista CBTecLE, São Paulo, v. 1, n. 1, 2017.

FREIRE, P. Pedagogia da autonomia: saberes necessários à prática. São Paulo: Paz e Terra, 1996.

FREIRE, P. (1968) Pedagogia do oprimido. São Paulo: Paz e Terra, 2019.

FRIGOTTO, G. Educação e trabalho: bases para debater a Educação Profissional Emancipadora. Perspectiva. Florianópolis, v.19, n.1, p.71-87, jan./jul., 2001.

GADOTTI, M. Trabalho e educação numa perspectiva emancipatória. In: II Fórum Mundial de Educação Profissional e Tecnológica: educação. emancipação e sustentabilidade. Florianópolis: Junho de 2012.

HIRATA, V. Crenças e práticas de aprender e ensinar inglês: conflito e dilema numa escola pública. Dissertação (mestrado) - Programa de Mestrado em Estudos de Linguagem, Instituto de Linguagens, Universidade Federal de Mato Grosso. 2012. 
HOOKS, B. Ensinando a transgredir: a educação como prática da liberdade. Trad. Marcelo Brandão Cipolla. São Paulo: Editora WMF Martins Fontes, 2017.

LANKSHEAR, C.; KNOBEL, M. Digital Literacy and Digital Literacies: policy, pedagogy and research considerations for education. Nordic Journal of Digital Literacy, 2006-2016, p. 8-20, 2015.

LINS, B. A.; MACHADO, B. F.; ESCOURA, M. Diferentes, não desiguais: a questão de gênero na escola. São Paulo: Editora Reviravolta, 2016.

MADEIRA, F. O sistema de crenças do aprendiz brasileiro de inglês: fatores que influenciam na construção de crenças. Trabalhos em Linguística Aplicada, Campinas, 47(1): 119-129, Jan./Jun., 2008.

MATTOS, A. M. A. O ensino de inglês como língua estrangeira na escola pública: novos letramentos, globalização e cidadania. Tese (Doutorado) - Programa de PósGraduação em Estudos Linguísticos e Literários em Inglês, Faculdade de Filosofia, Letras e Ciências Humanas, Universidade de São Paulo. 2011.

MIZAN, S. Práticas de letramento racial na formação de professores de língua inglesa: epistemologias pós-coloniais, pedagogia crítica e estéticas. In: JORDÃO, C. M.; MARTINEZ, J. Z.; MONTE MÓR, W. Letramentos em práticas na formação inicial de professores de inglês. Campinas: Pontes Editores, 2018.

NICOLAIDES, C. S.; MATOS, A. S.; MOTA, V. M. A autonomia na ensinagem de línguas: a oscilação entre o individual e o social. In: GERHARDT, A. F. L. M. (Org.). Ensino-aprendizagem na perspectiva da Linguística Aplicada. Campinas: Pontes Editores, 2013.

OLIVEIRA, A. P. G. Crenças de uma professora de língua inglesa: o papel do professor e as influências contextuais em foco. Dissertação (mestrado) - Departamento de Pós-graduação em Linguística Aplicada, Instituto de Letras, Universidade de Brasília. 2009.

OLIVEIRA, H. S.; MARIZ, D. Movimento Escola Sem Partido: uma leitura à luz de Paulo Freire. Revista Educação, Santa Maria, v. 44, p. 1-19, 2019.

ONODERA, J. Análise de necessidades em inglês para negócios. In: LIMA-LOPES, R. E; FISCHER, C. R.; GAZOTTI-VALliM, M. A. Perspectivas em linguas para fins especificos: festschrift para Rosinda Ramos. Campinas: Pontes Editores, 2015.

OXFORD, R. Toward a More Systematic Model of L2 Learner Autonomy. In: PALFREYMAN, D. (ed.) Learner autonomy across cultures. Great Britain: Macmillan, 2003. 
PENNYCOOK, A. Uma Linguística Aplicada transgressiva. In: MOITA LOPES, L. P. Por uma Linguística Aplicada indisciplinar. São Paulo: Parábola Editorial, 2006.

ROJO, R.Escol@ conectada: os multiletramentos e as TICs. São Paulo: Parábola, 2013.

FREIRE, P.; MOURA, E. Multiletramentos na escola. São Paulo: Parábola Editorial, 2012.

ROSSINI, A. M. Z. P.; BELMONTE, J. Panorama do ensino-aprendizagem de línguas para fins específicos: histórico, mitos e tendências. In: LIMA-LOPES, R. E; FISCHER, C. R.; GAZOTTI-VAlliM, M. A. Perspectivas em linguas para fins especificos: festschrift para Rosinda Ramos. Campinas: Pontes Editores, 2015.

SILVA, P. B. G. Educação das Relações Étnico-Raciais nas instituições escolares. Educar em Revista, Curitiba, Brasil, v. 34, n. 69, p. 123-150, maio/jun., 2018.

TAKAKI, N. H. Contribuições de teorias recentes de Letramentos Críticos para inglês instrumental. Revista Brasileira de Linguística Aplicada, v. 12, n. 04, p. 971-996, 2012.

TILIO, R. Ensino crítico de língua: afinal, o que é ensinar criticamente? In: JESUS, D. M.; ZOLIN-VESZ, F.; CARBONIERI, D. (Orgs.). Perspectivas críticas no Ensino de línguas: novos sentidos para a escola. Campinas: Pontes Editores, 2017.

TILIO, R. O livro didático contemporâneo: apresentação de uma proposta. In: MACIEL, R. F.; TILIO, R.; JESUS, D. M.; BARROS, A. L. E. C. Linguística Aplicada para além das fronteiras. Campinas: Pontes Editores, 2018.

VETROMILLE-CASTRO, R. O professor de línguas e as tecnologias digitais: reflexões sobre a profissão na sociedade conectada. In: FINARDI, K. R.; TILIO, R.; BORGES, V.; DELlAGNElO, A.; FILHO, E. R. (Org.). Transitando e transpondo $n(a)$ Linguística Aplicada. Campinas: Pontes Editores, 2019.

WENDEN, L. A. Metacognitive knowledge and language learning. Applied Linguistics, 19/4, p. 515-537, 1998.

Recebido em 11 de maio de 2020

Aceito em 02 de junho de 2020 